\title{
DA POLARIZAÇÃo À BUSCA PELO EQUILÍBRIO: AS RELAÇÕES ENTRE INTERNET E PARTICIPAÇÃO POLÍTICA 12
}

\author{
Jaqueline Resmini Hansen ${ }^{3}$ \\ Maria Alice Silveira Ferreira ${ }^{4}$
}

\begin{abstract}
RESUMO
O Estado e a sociedade civil possuem uma relação muitas vezes tensionada e conflituosa, apesar de fundamental no contexto democrático ocidental. Estas instâncias, por sua vez, têm encontrados inúmeros desafios em função dos impactos da popularização do acesso à internet. Este artigo se situa nesta interconexão entre internet e democracia e objetiva analisar como a literatura sobre participação política tem abordado essa relação, apresentando as principais perspectivas teóricas a esse respeito. Assim, mostramos como as perspectivas iniciais eram mais estanques e polarizadas, bem como os movimentos no campo para que se adotasse uma abordagem mais flexível e complexa, que leva em conta as diversas características individuais, contextuais e da tecnologia em si, importantes para se pensar o impacto da rede nas atividades políticas off-line, mas, também, o surgimento de um ativismo estritamente on-line. Portanto, a literatura tem considerado que a internet alcançou um papel central para o entendimento do ativismo político, principalmente de protesto, a qual atua sobre a sua organização, suas formas e modalidades. Por outro lado, considera-se que a internet apresenta empecilhos em relação às possibilidade de controle de dados, privacidade e vigilância.
\end{abstract}

Palavras-chave: Internet. Democracia. Participação política.

\begin{abstract}
State and civil society have a tension relationship, confflited many times, but fundamental in the ocidental democratic context. They have found Challengers in the impacts of the popularization of the internet. This paper is in this interconection between internet and democracy and intents to analyse how the literature about political participation has abord this relationship, presenting the main theorical perspectives about the subject.

We showed how the initial perspectives was more pounds and polarized, as movements in field to adopt one approach more complex and flexible, witch bring to debate individual, contextuals and the technology characteristics, very important to think the impact of the internet in political activity off-line, but also the rising of an ativism online only. There for, the literature had considered that the internet has achive the central role to understand the political ativism, specially protests, witch have a important role in the organization and your shapes and forms. But, we considered that the internet have barries about the possibilites of datas control, privacy and surveillance.
\end{abstract}

Keywords: internet, democracy, political participation.

\section{RESUMEN}

El Estado y la sociedad civil poseen una relación muchas veces tensada y conflictiva, aunque fundamental en el contexto democrático occidental. Estas instancias, a su vez, han encontrado innumerables desafíos en función de los impactos de la popularización del acceso a Internet. Este artículo se sitúa en esta interconexión entre internet y democracia y objetiva analizar cómo la literatura sobre participación política ha abordado esa relación, presentando las principales perspectivas teóricas a ese respecto. Así, mostramos cómo las perspectivas iniciales eran más estancas y polarizadas, así como los movimientos en el campo para que se adopta un enfoque más flexible y complejo, que tiene en cuenta las diversas características individuales, contextuales y de la tecnología en sí, importantes para pensar el impacto de la red en las actividades políticas fuera de línea, pero también el surgimiento de un activismo estrictamente on-line. Por lo tanto, la literatura ha considerado que Internet ha

\footnotetext{
${ }^{1}$ Enviado: 31/10/2017. Aceito: 10/11/2017.

2 DOI: http://dx.doi.org/10.5380/recp.v9i1.56124

3 Doutoranda em Ciência Política na UFMG. Bolsista Capes e integrante do Centro de Estudos do Comportamento Político (CECOMP) e do Centro de Pesquisa em Política e Internet (CEPPI). E-mail: Jaqueline.hansen@live.com

${ }^{4}$ Doutoranda em Ciência Política pela UFMG. É bolsista Capes do Instituto da Democracia e da Democratização da Comunicação e sub-coordenadora do Centro de Pesquisas em Política e Internet (CePPI). E-mail: m.alicesilveira@gmail.com
} 
alcanzado un papel central para el entendimiento del activismo político, principalmente de protesta, la cual actúa sobre su organización, sus formas y modalidades. Por otro lado, se considera que Internet presenta obstáculos en relación a las posibilidades de control de datos, privacidad y vigilancia.

Palabras claves: Internet. Democracia. Participación política.

\section{INTRODUÇÃO}

Os meios de comunicação ${ }^{5}$ de massa sempre tiveram um papel importante na construção da vida política e social de uma sociedade. Conforme esses meios foram se desenvolvendo, ao longo da história, eles passaram a representar importantes instrumentos mobilizados pelos indivíduos para compreender o mundo e foram capazes de fomentar importantes mudanças no contexto social. Dessa forma, grande parte da ação política é comunicacional e informacional (FERREIRA, 2015). Isso porque os meios de comunicação se tornam centrais na luta pela redefinição de valores democráticos, sendo capazes de construir significados para o processo político global e politizar as populações (DAHLBERG; SIAPERA, 2007).

Nesse sentido, o surgimento das tecnologias de informação e comunicação e a ampliação dos usos da internet nos últimos anos trouxe novas modificações à vida social e política das sociedades contemporâneas. Com a potencialização da ausência do lugar comum, a comunicação pode ser instantânea mesmo em locais distantes (BENTIVEGNA, 2006; HJAVARD, 2012; THOMPSON, 1998).

Diante disto, as novas tecnologias de comunicação e informação se colocam como uma questão a ser considerada dentro dos estudos que abordam a democracia e seu modus operandi. Assim sendo, é na interseção entre o debate sobre política e o debate a respeito da internet que esta discussão se coloca. Partimos do entendimento de que a revolução nos meios de comunicação pauta novas questões para a compreensão do campo político, seja em suas instituições e processos, como para a análise do fazer político por meio dos cidadãos, ou nas perspectivas participativas e comportamentais. Por conseguinte, indagamos como a literatura tem discutido o papel da internet e suas affordances ${ }^{6}$ para pensar a participação política.

Diante disso, objetivamos por meio de uma inserção bibliográfica profunda apresentar as nuances e mudanças que este campo interpretativo vem delineando neste início do século XXI. Assim, por meio do diálogo com esta literatura que discute a internet e seu

\footnotetext{
${ }^{5}$ Stig Hjavard (2012, p. 66) define os meios de comunicação como "tecnologias que expandem a comunicação no tempo, no espaço e na modalidade".

6 "Affordances" referem-se às características estruturais das diferentes plataformas existentes no ambiente online, sendo, portanto, as particularidades que diferenciam e caracterizam blogs e outras plataformas digitais, como o Twitter, o Facebook e o YouTube.
} 
HANSEN, J; FERREIRA, M. A. S. Da polarização à busca pelo equilíbrio: as relações entre internet e participação política

potencial democrático, iremos demonstrar como o campo foi se amplificando ao longo dos anos em decorrência das rápidas e constantes modificações na tecnologia per se, mas também das relações e práticas do indivíduo e de suas consequências sociais e políticas. Assim, se inicialmente as pesquisas se polarizaram entre o bem, o mal e a indiferença, com o decorrer do tempo mostrou-se a necessidade de se pautar tanto o lado positivo quanto o negativo de tais meios de comunicação - ou seja, tanto a integração com o ambiente off-line quanto a independência do ambiente on-line; tanto a reprodução de desigualdade quanto as capacidades de minimizá-las; e tanto o potencial democrático e libertário quanto o controle e o cerceamento dos indivíduos e de suas liberdades.

Este artigo se divide em quatro partes, além desta. Na primeira parte, denominada "Dos entusiastas aos pessimistas: o debate inicial", apresentamos as principais características e limitações dos primeiros estudos e interpretações a respeito dos efeitos da internet sobre a democracia em geral. Na segunda parte, intitulada "Em busca de um realismo: os olhares que integram múltiplas dimensões", buscamos demonstrar como as interpretações a esse respeito passaram a dialogar no campo normativo da democracia em geral e da participação em particular, através de debates empíricos e de uma perspectiva multidimensional. Na terceira parte, por fim, apresentamos a recente discussão sobre o impacto do grande número de informações provenientes da internet e as questões da privacidade nesse meio.

\section{DOS ENTUSIASTAS AOS PESSIMISTAS: O DEBATE INICIAL}

Inicialmente, os teóricos da Ciência Política, ao olharem para a internet, dedicaramse a debater os potenciais democráticos da tecnologia a partir de um caráter normativo. É importante ressaltar que, neste primeiro momento, a perspectiva de democracia deliberativa servia de principal norte para o debate, dividindo os pesquisadores entre aqueles que viam na internet um caminho para a superação das falhas da democracia representativa e para o crescente empoderamento da perspectiva deliberacionista, e aqueles que não acreditavam neste potencial ou, então, viam a internet como um mecanismo aprofundador das desigualdades. Assim, a discussão sobre a internet passava pelo debate entre os "ciberotimistas", os "ciberpessimistas" e aqueles que não viam a tecnologia como algo nem bom nem ruim, os "cibercéticos" (MARGETTS, 2013; MOSSBERGER, 2009; NORRIS, 2001).

Os "ciberotimistas" olhavam a rede como algo capaz de aprofundar e corrigir essas falhas da democracia representativa. Para eles, a internet seria capaz de mobilizar indivíduos 
desengajados, pois a sua estrutura comunicacional interativa apresentaria novas oportunidades para tal - isso porque ao diminuir a necessidade de recursos, como o tempo, e ampliar o acesso à informação, ela capacitaria os indivíduos a atuar politicamente. Dentro desta perspectiva, a internet representava a aurora de uma nova era de democracia, oferecendo novas formas de participação em esferas públicas globais e em movimentos de base para desafiar os interesses dominantes (EARL; KIMPORT, 2011; MARGETTS, 2013).

Neste sentido, a web poderia criar "arenas de debates públicos espontâneos, flexíveis e autogovernados" (CHADWICK, 2009, p. 14), de modo que os usos políticos da internet seriam um efeito de mídia, ou seja, a interação com a tecnologia levaria os cidadãos a perceberem que a internet amplia o acesso à informação política, sendo que, com isso, eles passariam a se envolver mais nos assuntos públicos, interagindo com novas perspectivas para a deliberação pública - e este aspecto seria revolucionário para a maneira com fazemos política (MARGETTS, 2013; MOSSBERGER, 2009; NORRIS, 2001).

Os "ciberpessimistas", por sua vez, defendiam que a internet não possui um efeito mobilizador; pelo contrário, ela atuaria reforçando as estruturas que estão postas, aumentando as clivagens sociais já existentes, pois os engajados se tornariam mais engajados e os desengajados, mais desengajados. Portanto, a tecnologia atuaria como um filtro selecionando apenas aqueles que já estão mobilizados, apresentando novas oportunidades participativas para estes cidadãos. Nesta perspectiva, os usos políticos do ambiente on-line ocorreriam em função de um efeito de seleção, de modo que o engajamento off-line anterior é que seria o responsável por fazer o indivíduo perceber as oportunidade de ação política na web e usufruir delas. Deste modo, a web não desenvolveria motivações e interesses por política, mas apenas ampliaria o acesso à informação política e o conhecimento deste âmbito para aqueles já predispostos a isso. Com isto, muitos autores acreditavam que, com a internet, as pessoas se manteriam cada vez mais isoladas no mundo on-line (NIE; ERBRING, 2000 apud EARL; KIMPORT, 2011), a ponto de assumirem grandes níveis de anonimato, já que, nesse novo ambiente, poderiam assumir falsas identidades. Nesse sentido, esses pesquisadores argumentam que as novas tecnologias não poderiam propiciar uma maior participação: pelo contrário, poderiam levar a uma maior vigilância do Estado e dos atores comerciais sobre os cidadãos, acentuando, cada vez mais, a desigualdade social (NORRIS, 2001; MARGETTS, 2013).

Por fim, os "cibercéticos" defendiam que as novas tecnologias de comunicação e informação não seriam capazes de modificar o status quo vigente, pois elas se adaptariam ao sistema político e social de tal modo que não conseguiriam criar novas oportunidades 
HANSEN, J; FERREIRA, M. A. S. Da polarização à busca pelo equilíbrio: as relações entre internet e participação política

participativas nem modificar as estruturas do comportamento já existentes. Este debate normativo, apresentado até o momento, limita seu olhar apenas à tecnologia, no seu aspecto mais estrutural - ou seja, à sua capacidade interativa - e, ao focar nisso, pensa a relação entre internet e participação política em um espectro unidimensional, atendo-se, portanto, aos efeitos da tecnologia (MARGETTS, 2013; MOSSBERGER, 2009; NORRIS, 2001).

\section{EM BUSCA DE UM REALISMO: OS OLHARES QUE INTERAGEM MÚLTIPLAS DIMENSÕES}

Passado esse primeiro movimento, que procurava postular o efeito da internet sobre a política e, mais especificamente, sobre a democracia, os pesquisadores passaram a olhar para a tecnologia de maneira mais interativa, guiados pela ideia de que, assim como não explicamos a vida social e política por meio de apenas uma dimensão (mas de várias delas), com a internet não seria diferente. Os estudos caminharam para uma discussão empírica da relação entre web e participação política e, deste modo, as pesquisas desenvolvidas no início dos anos 2000 foram fundamentais para evidenciar que a relação entre internet e participação política não é impactada apenas de um lado, da mesma forma que seus efeitos assumem as características mais diversificadas.

Pippa Norris (2001) faz um esforço inicial pela superação desta polaridade e passa a pensar um modelo para o engajamento on-line. Para a autora, a internet, enquanto meio de comunicação, pode ser pensada a partir do modelo do círculo virtuoso, isto é, da ideia de que a mídia em geral é incapaz de mobilizar contingentes apáticos ao processo político, sendo que, portanto, a internet teria um caráter apenas reforçador, tornando os engajados mais engajados e não engajados, menos engajados. Assim, o fato de a internet se apresentar como uma mídia da escolha é, também, um aspecto reforçador, pois as experiências anteriores ao contato com a rede teriam um papel importante para nortear as atividades no ciberespaço. Por outro lado, a autora argumenta que as novas tecnologias de comunicação e informação podem ser revolucionárias, ao passo que se apresentam como um local profícuo para a disseminação dos chamados "novos movimentos sociais", os quais, por sua lógica desterritorializada e pósmaterialista, conseguem se fortalecer no ambiente on-line e influenciar valores e atitudes na sociedade. Entretanto, apesar da tentativa de apresentar uma perspectiva múltipla, o modelo apresentado por Norris ainda apresenta uma carga fortemente pessimista.

O passo dado por Pippa Norris no início do século XXI repercutiu dentro do campo de forma ampla. Concomitante a isto, pesquisas desenvolvidas nos anos seguintes 
encontraram evidências empíricas que mostravam o ambiente on-line como um espaço com duplo potencial, sendo eles os de trazer novas formas de ação e novas vozes ao espaço público e, também, de potencializar e fortalecer as já existentes. Deste modo, apesar de muitas vezes as análises penderem para um "pessimismo" ou um "otimismo", o movimento adotado posteriormente foi o de se passar a buscar um equilíbrio entre estes polos (CHADWICK, 2009).

O campo tem reconhecido que a internet e suas affordances podem transformar as instituições tradicionais e a organização política dos sistemas democráticos ao facilitar a participação dos cidadãos na vida democrática, minimizando os efeitos da queda no nível de engajamento nos canais tradicionais de participação (FUNG, 2006). De acordo com Cardon (2012), a web é capaz de proporcionar experiências que vão além da relação entre representantes e representados. "Ela não permite somente comunicar mais, melhor e mais rápido; ela alarga formidavelmente o espaço público e transforma a própria natureza da democracia" (CARDON, 2012). Entretanto, também tem sido discutido o potencial do ambiente digital de reproduzir as desigualdades sociais e reforçar os privilégios daqueles que já se encontram em posição central na sociedade (BEST; KRUEGER, 2005; NORRIS, 2001; MOSSBERGER, 2009).

Deste modo, partindo desta ideia de equilíbrio entre dois polos, Xenos e Moy (2007) demonstram que os efeitos da web sobre a participação política podem ser compreendidos como efeitos instrumentais e psicológicos. É um efeito instrumental na medida em que possui uma força positiva para a cidadania democrática, pois amplia o acesso à informação e apresenta novos repertórios para ação (ao mesmo tempo que os articula com os já ativados), e um efeito psicológico devido ao fato de a participação e conversação on-line dependerem das características psicossociais do internauta, as quais revelam a centralidade do interesse na explicação de como os indivíduos usam a rede.

Durante os anos 2000, a tese iniciada por Norris (2001) de que o potencial da internet sobre o engajamento tem um caráter duplo ganha corpo empírico, além de outras nomenclaturas na literatura ${ }^{7}$. Um estudo realizado por Pippa Norris e John Curtice (2006) com a população britânica evidencia que os mais jovens, com maior acesso à informação e mais educados, são mais ativos on-line, além de mostrar que a internet fortalece as modalidades contestatórias de ação, indicando que pensar em termos de "mobilização e

\footnotetext{
7 Da mesma forma que Pippa Norris (2001) fala em "caráter reforçador e revolucionário", Hellen Margetts (2013) fala em "reforço e normalização da participação" e Rachel Gibson e Marta Cantijoch (2013) falam em "integração e independência", como desenvolveremos ao longo do texto.
} 
HANSEN, J; FERREIRA, M. A. S. Da polarização à busca pelo equilíbrio: as relações entre internet e participação política

reforço" é profícuo para o debate. A pesquisa foi pioneira ao comprovar o caráter multidimensional da ação on-line, característica observada na população britânica, anos mais tarde, por Gibson e Cantijoch (2013), além de também ter sido evidenciada no contexto brasileiro por Ribeiro, Borba e Hansen (2016) e por Oliveira et al. (2016).

No mesmo caminho, a tese de Margetts (2013) também apresenta suporte empírico ao caráter profícuo de uma leitura em prol do equilíbrio. Ao analisar o público britânico, a autora descobre que, no tocante à igualdade política, as redes digitais reforçam as clivagens existentes; porém, no que diz respeito ao controle popular da democracia, a web contribui para a fragmentação dos grupos políticos, tornando o sistema político mais fluído e caminhando para a normalização da participação. Hafner-Fink e Oblak Črnič (2014) também se inserem no debate acerca da mobilização e do reforço, analisando dados sobre a população eslovena. Os pesquisadores descobrem que as modalidades presenciais de ação encontram local para se reproduzirem no universo on-line, bem como apontam evidências de que a participação off-line fortalece a participação on-line - assim como outros fatores, estando entre eles ter entre 18 e 35 anos, ser homem e possuir nível superior. Os autores também mostram que as modalidades de protesto são fortalecidas pela web, o que respalda a tese do reforço. Por outro lado, Hafner-Fink e Oblak Črnič (2014) encontram, entre os eslovenos, cidadãos que estão ativos apenas nas modalidades digitais, fortalecendo a tese da mobilização.

Brundidge e Rice (2009) também encontraram uma relação positiva entre engajamento on-line e off-line entre os estadunidenses, suplementando a tese do reforço. Essa pesquisa indicou que as novas tecnologias de comunicação e informação favorecem a heterogeneidade da discussão política. Os autores também confirmam que os cidadãos com altos nível socioeconômicos, conhecedores dos assuntos políticos e ativos presencialmente são mais propensos a usarem os recursos da rede, assim como os mais jovens, mais educados e mais afluentes. Mossberger (2009), analisando também os Estados Unidos, encontrou resultados semelhantes, pois os brancos, mais jovens, mais educados e com maiores rendas possuem mais chances de serem ciberativistas, em comparação com os negros, mais velhos, com menores rendas e com menor acesso à educação.

Gibson e Cantijoch (2013) também trazem valorosas contribuições para o debate, utilizando das ideias de "integração" e "independência" entre o ambiente on-line e off-line e da ideia de "replicação e diferenciação". As autoras estão interessadas em saber se as modalidades digitais de ação política são meramente réplicas das presenciais e se os indivíduos ativos fundem os dois ambientes em um processo de integração, sem que exista independência entre eles. Ao analisar dados sobre a população inglesa, as pesquisadoras 
concluem que existe uma forte tendência à replicação. Porém, em relação à independência ou integração, os resultados não são conclusivos: por um lado, indicam uma integração entre os espaços nos tipos mais concretos de participação (como a doação de dinheiro); por outro, mostram certa independência entre as formas mais passivas de participação, indicando que, apesar da existência robusta de uma replicação, o ciberespaço pode funcionar como base social para um tipo específico de comportamento. Diante disso, para as autoras, as modalidades de participação podem ser pensadas, nos ambientes presenciais e digitais, em termos eleitorais-partidários, de atividades de protesto, de contato, comunitárias e de ativismo de consumo. Além disso, as autoras também consideram as modalidades, digitais e presenciais, de engajamento passivo, nas categorias de atenção à informação, discussão política e atividades de expressão de preferências políticas.

Oser, Hooghe e Marien (2013), ao analisarem a população estadunidense, descobrem que os ciberativistas também estão ativos off-line, mas que se diferenciam dos que estão ativos somente presencialmente por darem maior ênfase ao ambiente digital. Entretanto, devido ao fato de a participação on-line não ser apenas uma reprodução das modalidades presenciais, os autores afirmam que a ação política na web se configura como um tipo distinto de participação. Em relação às características daqueles que estão ativos no ciberespaço, os pesquisadores descobriram que eles possuem os mesmos padrões socioeconômicos que os ativistas presenciais, apesar de diferirem substancialmente destes no que diz respeito à idade (os mais jovens são mais propensos a estarem ativos on-line).

Estes estudos que mostram que a internet pode atuar tanto no sentido de mobilização de novos atores como no sentido de reforçar o engajamento dos já ativos, como demonstramos, também procuraram entender quais elementos condicionam a participação política no ambiente on-line, indagando se eles seriam os mesmo do ambiente off-line. No campo do comportamento político, o "Modelo do Voluntarismo Cívico" de Verba, Schlozman e Brady (1995) é amplamente utilizado para entender os condicionantes da ação política. Os autores advogam que a participação ocorre em função de motivações e capacidades, sendo que estas podem ser analisadas a partir de três categorias: recursos - tempo, dinheiro e habilidades cívicas —, engajamento psicológico e redes de recrutamento. A ideia de "capacidade" refere-se à necessidade de recursos que são combinados de diferentes maneiras nas diversas modalidades de ação. O engajamento psicológico se refere aos valores e interesses que estão implícitos na ação humana e, portanto, está relacionado tanto à capacidade de utilizar os recursos, quanto às motivações psicológicas para tal - como o interesse, o conhecimento político e o sentimento de eficiência dos agentes. As motivações 
HANSEN, J; FERREIRA, M. A. S. Da polarização à busca pelo equilíbrio: as relações entre internet e participação política

também podem ser externas e se referirem às redes de recrutamento. Neste sentido, os estudiosos do comportamento que se dedicaram a entender os condicionantes do engajamento on-line encontraram evidências de que fatores relacionados ao modelo supracitado (como alta escolaridade, interesse por política, conhecimento no assunto, pertencimento a níveis socioeconômicos mais altos e habilidades cívicas) são importantes para o entendimento do fenômeno (BRUNDIDGE; RICE, 2009; HAFNER-FINK; ČRNIČ, 2014; MOSSBERGER, 2009; NORRIS, 2001; NORRIS; CURTICE, 2006; OLIVEIRA et al., 2016; OSER; HOOGHE; MARIEN, 2013; RIBEIRO; BORBA; HANSEN, 2016).

Diante disto, as evidências empíricas encontradas nestes estudos ao longo dos anos mostram o caráter múltiplo do ambiente on-line: de recrutar, mobilizar e reforçar a participação. Além disso, e especialmente, evidenciam que existe uma continuidade de interesses entre os ambientes (LIVINGSTONE, 2011) e, deste modo, uma convergência entre on-line e off-line (DAHLGREN, 2005), que implica a impossibilidade de se fazer separações entre eles e a necessidade de pensá-los em conjunto.

Assim, as discussões recentes apontam que as novas tecnologias podem ser aliadas da ação coletiva, pois diminuem alguns dos custos da participação política, facilitando as formas de adquirir informações e o engajamento dos cidadãos (EARL; KIMPORT, 2011; MARGETTS, 2013; CARDON, 2012; DELLA PORTA, 2013; RIBEIRO; BORBA; HANSEN, 2016; BORGE; CARDENAL, 2011 apud MARGETTS, 2013). Alguns estudos têm mostrado que a internet pode facilitar a mobilização de novos indivíduos e grupos que, tradicionalmente, não participariam da vida política (BORGE; CARDENAL, 2011 apud MARGETTS, 2013; ANDUIZA et al., 2010 apud MARGETTS, 2013; BOND et al., 2012). Outros indicam que o espaço on-line tem propiciado novas - e diferentes - formas de participação, principalmente com o advento da "Web 2.0", que possibilitou às pessoas escreverem suas ideias em blogs ou sites e expressarem suas opiniões políticas nas redes sociais (CHADWICK, 2009; GIBSON; CANTIJOCH, 2013; HINDMAN, 2009; OSER; HOOGHE; MARIEN, 2013). Ainda, as redes sociais possuem um papel importante na interação entre o ativismo presencial e a "e-participação" (VALENZUELA; ARRIGADA; SCHERMAN, 2012; VALENZUELA, 2014).

De tal modo, atualmente é aceito pela comunidade que a participação política é um fenômeno que tem múltiplas direções e dimensões, sendo um tipo de ação que, ao mesmo tempo em que se integra ao ambiente off-line, ocorre também independentemente dele (GIBSON; CANTIJOCH, 2013; NORRIS; CURTICE, 2006; RIBEIRO; BORBA; HANSEN, 2016; OLIVEIRA et al., 2016; OSER; HOOGHE; MARIEN, 2013). Isto quer dizer que o 
meio digital reproduz modalidades de participação política off-line, mas que, em decorrência de suas affordances, a internet se apresenta por si só como uma importante ferramenta para o ativismo, principalmente o de protesto, bem como produz novas formas de participação que, embora possam ser mais passivas, se configuram como atividades essencialmente on-line (GIBSON; CANTIJOCH, 2013; TEOCHARIS, 2015; OSER; HOOGHE; MARIEN, 2013; VALENZUELA; ARRIGADA; SCHERMAN, 2012; OLIVEIRA et al., 2016). Deste modo, a rede permite uma maior liberdade de expressão e diminui os custos das informações políticas que permitem a participação nas instituições democráticas e nas ações coletivas (MARGETS, 2013).

Este movimento do campo de pesquisa que aborda as relações entre participação política e internet nos traz a questão da existência de um tipo específico de participação, caracterizada como on-line (GIBSON; CANTIJOCH, 2013; OSER; HOOGHE; MARIEN, 2013). Assim, se pensarmos a participação política como um conjunto de atos voluntários que visam mobilizar mecanismos que auxiliem os indivíduos a comunicar ao Estado e à sociedade suas opiniões, preferências e demandas (VERBA; SCHLOZMAN; BRADY, 1995), o on-line pode ser entendido como uma categoria, assim como a participação eleitoral ou a participação de protesto. Diante disso, nos últimos anos os pesquisadores do campo têm procurado estabelecer as particularidades da participação on-line, a qual pode se realizar tanto nos ambientes formais (como os sites e páginas do governo) quanto nas redes sociais. Ainda, visam demonstrar que, apesar de ainda não ter uma definição precisa, a participação on-line é genericamente categorizada como uma atividade personalizável e individual (BENNETT; SEGERBERG, 2013; MILAN, 2015; MENDONÇA; AMARAL, 2016; TUFEKCI, 2014), sendo que a exposição da mobilização dos agentes ativa as redes sociais às quais estão conectados e aumenta a conscientização acerca de problemas sociais e políticos, de forma que a internet atua como um local onde podem-se exercer pressões sociais ou políticas para a resolução destes problemas (THEOCHARIS, 2015)

Dessa forma, podemos dizer que as atividades políticas executadas exclusivamente no ambiente digital tendem a se diferenciar das presenciais em função dos recursos que acionam (BEST; KRUEGER, 2005). Assim, a ação política no ambiente on-line tem um menor custo executivo (principalmente nas redes sociais, já que são necessários apenas alguns cliques para pôr em prática tal ação), mas um maior custo simbólico, principalmente perante a rede pessoal. Outro ponto importante que destaca a diferença do on-line em relação ao off-line é a centralidade do aspecto individual e personalizado da atividade política na internet, o qual, apesar de presente em muitas modalidades de ação off-line, não se configura como uma de 
HANSEN, J; FERREIRA, M. A. S. Da polarização à busca pelo equilíbrio: as relações entre internet e participação política

suas características definidoras. Assim, a participação on-line pode ser entendida em função do indivíduo, uma vez que, principalmente nos casos em que ocorrem ações em redes sociais, o primeiro destinatário da ação é a rede pessoal, de forma que o governo figura em segundo plano - embora, na maioria das vezes, o governo seja o principal destino da ação (THEOCHARIS, 2015; TUFEKCI, 2014; OSER; HOOGHE; MARIEN, 2013).

Tais características da participação on-line apontam para um paradigma digital de cidadania, e Karen Mossberger (2009) argumenta que apenas a literacia unida à tecnologia faz com que as habilidades técnicas sejam desenvolvidas de modo a garantir a formação de uma cidadania digital capaz de fomentar igualdade de voz e representação. O avanço neste debate mostra que este novo paradigma de cidadania apresenta tendências de afastar das instituições políticas tradicionais a representação de suas vozes, evidenciando-se, deste modo, a principal diferença entre o off-line e on-line: a delegação da voz (TUFEKCI, 2014). Enquanto no primeiro as atividades políticas são mecanismos que delegam a representação da voz a uma instituição abstrata — o partido, o sindicato, o movimento social ou o coletivo —, no segundo evita-se delegar a representação da voz, esta é retomada para si, de modo que a identificação pessoal é central (THEOCHARIS, 2015; TUFEKCI, 2014; OSER; HOOGHE; MARIEN, 2013).

\section{A CRÍTICA NECESSÁRIA: OS NOVOS DEBATES SOBRE A PRODUÇÃO DE INFORMAÇÕES PESSOAIS E AS MUDANÇAS NA PRIVACIDADE}

As recentes discussões sobre o potencial democrático da internet nos mostram a necessidade de se debater assuntos ainda pouco investigados pela literatura (TRERÉ, 2016). Este debate tem chamado a atenção para a questão acerca do controle de dados, informações e privacidade por parte de governos democráticos, autoritários e grandes corporações (TRERÉ, 2016; SILVEIRA, 2009). De acordo com Treré (2016), a maioria dos estudos atuais enfatiza os usos das plataformas digitais mostrando os potenciais que oferecem aos cidadãos, sem abordarem seus limites e riscos e as ameaças que apresentam aos processos democráticos.

Nesse sentido, autores como Treré (2016) e Milan (2015) consideram necessário enxergar as ações políticas a partir de um olhar sociotécnico. Para Milan (2015), essas ações devem ser compreendidas e analisadas considerando-se a política dessas plataformas, levando-se em conta suas estratégias, dinâmicas e economias. Segundo a autora, os algoritmos, por exemplo, são fundamentais, pois sustentam as mídias sociais e formam 
dimensões simbólicas de dissidência, como identidades e narrativas coletivas (MILAN, 2015; CREPALDE; FERREIRA, 2017).

Dessa forma, podemos entender que as ações políticas estão cada vez mais moldadas por processos algorítmicos (TRERÉ, 2016). Isso reforça a ideia da não neutralidade das mídias sociais. As suas affordances e a natureza algorítmica fazem com que as mídias se tornem atores com direitos próprios, capazes de intervir no processo de criação de significados dos atores sociais (MILAN, 2015). Os resultados dessas ações, por sua vez, são frutos das interações dessas affordances com seus usuários.

Um exemplo disso é a constante criação de "bolhas" dentro das plataformas. Para Pariser (2012), as bolhas são mecanismos criados para filtrar e refinar informações que atendam especificamente a cada indivíduo, criando-se um universo exclusivo de informação para cada pessoa. Essa personalização é uma das estratégias usadas na maioria das mídias sociais. Para o autor, essas bolhas podem apresentar perigos para a democracia. Isso porque podem afetar nossa capacidade de decidir o que e como queremos viver. Além disso, elas trazem menos chances de vivências e aprendizados distintos dos que já conhecemos, reforçando o debate apenas entre iguais (PARISER, 2012).

Da mesma forma, o volume de dados criado nos últimos anos ("Big Data”) tem sido aplaudido como grande inovação de forma acrítica. Para Treré (2016), é preciso entender as consequências do que ele chama de "giro computacional" nas mais diversas disciplinas, levando-se em conta esferas da epistemologia, da ontologia e da ética. Além disso, também é crucial investigar os erros e limitações na coleta e na interpretação desses dados. Assim, é importante que se possa examinar como e com que intensidade essas affordances têm sido apropriadas por cidadãos, governos e grandes corporações, além de quais serão os avanços e desafios para as democracias contemporâneas trazidos por elas.

\section{APONTAMENTOS E CONSIDERAÇÕES FINAIS}

O debate sobre os potenciais democráticos propiciados pela internet tem sido tema de discussão recorrente entre estudiosos do assunto nos últimos anos. Desde 1980, pesquisadores vêm tecendo argumentos, dos mais céticos aos mais entusiastas, sobre o potencial participativo e democrático das mídias digitais. Atualmente, há um crescente de estudos indicando que a internet pode propiciar ambientes e ferramentas para o engajamento, recrutando e mobilizando cidadãos em torno de pautas políticas e sociais, bem como promovendo modalidades específicas de participação. Portanto, em decorrência da rede, 
HANSEN, J; FERREIRA, M. A. S. Da polarização à busca pelo equilíbrio: as relações entre internet e participação política

emergiram novas formas de organização, interação e comunicação, bem como novos atores e repertórios de ação que se estruturam dentro de uma lógica política desterritorializada. Deste modo, o ciberespaço propicia um ambiente e ferramentas com os quais os mais diferentes grupos sociais e movimentos podem atuar, se estruturar e se expressar (BARBER, 2003; BENNETT; SEGERBERG, 2013; BENTIVEGNA, 2006; GIBSON; CANTIJOCH, 2013; MARGETTS, 2013; NORRIS, 2001; NUNES, 2014; OSER; HOOGHE; MARIEN, 2013).

Diante disso, podemos concluir que, apesar de inicialmente a web ter sido olhada por óticas estanques - entre salvar e destruir a democracia —, o passar dos anos mostrou, em particular para os estudiosos da participação política, que, acima de um debate sobre ser "boa", "ruim" ou "irrelevante", a internet é um fato dentro do contexto social atual. Deste modo, as pessoas utilizam a rede das mais diversas formas e com diferentes objetivos, atribuindo-lhe diferentes significados, inclusive políticos. Contudo, para além disso, a grande inserção da internet no cotidiano ajuda a modificar os significados políticos, sociais e psicológicos que atribuímos às nossas vidas particulares e ao mundo em geral. Deste modo, mais do que determinar se isso é bom ou ruim para a democracia, o debate a esse respeito deve pautar-se na ideia de que a internet é uma realidade, sendo necessário pensar e compreender como esse novo espectro da vida social se relaciona com a participação política, ressignificando-a, modificando-a e trazendo novos ambientes para ação.

\section{REFERÊNCIAS}

BARBER, B. Strong Democracy: Participatory Politics for New Age. California: University of California Press, 2003.

BENNETT, W. L.; SEGERBERG, A. The Logic of Connective Action: Digital Media and the Personalization of Contentious Politics. New York: Cambridge, 2013.

BENTIVEGNA, S. Rethinking Politics in the World of ICTs. European Journal of Communication, v. 21, n. 3, p. 331-343, July 2006.

BEST, S. J.; KRUEGER, B. Analyzing the Representativeness of Internet Political Participation. Political Behavior, v. 27, n. 2, p. 183-216, June 2005. Disponível em: $<$ http://www.jstor.org/stable/4500191>. Acesso em: jan. 2010.

BOND, R. et al. A 61-milion-person Experiment in Social Influence and Political Mobilization. Nature, v. 489, Sept. 2012.

BRUNDIDGE, J.; RICE, R. Political Engagement Online: do the Information Rich Get Richer and the Like-Minded more Similar? In CHADWICK, A.; HOWARD, P. The Routledge Handbook of Internet Politics. New York: Routledge, 2009. 
CARDON, D. A democracia internet: promessas e limites. Rio de Janeiro: Forense Universitária, 2012.

CHADWICK, A. Web 2.0: New Challenges for the Study of E-Democracy in an Era of Informational Exuberance. A Journal of Law and Policy for the Information Society, v. 5, n. 1, p. $1-42,2009$.

CREPALDE, N.; FERREIRA, M. A. S. Mídias sociais e polarização política: a repercussão da PEC 55 no Twitter e no Facebook. Artigo apresentado no $41^{\circ}$ Encontro Anual da Anpocs, 2017.

DAHLBERG, L.; SIAPERA, E. Tracing Radical Democracy and Internet. In: Radical Democracy and the Internet: Interrogating Theory and Practice. New York: Palgrave Macmillan, 2007.

DAHLGREN, P. Internet, Public Spheres and Political Communication: Dispersion and Deliberation. Political Communication, n. 22, p. 147-162, Aug. 2005.

DELLA PORTA, D. E-Democracy? New Technologies and Democratic Deepening. In: Can Democracy Be Saved? Participation, Deliberation and Social Movements. Cambridge: Polity Press, 2013.

EARL, J.; KIMPORT, K. Digitally Enabled Social Change. Massachusetts: MIT Press, 2011.

FERREIRA, M. A. S. \#BHNASRUAS: uma análise do confronto político contemporâneo a partir de páginas do Facebook. Belo Horizonte, Universidade Federal de Minas Gerais. (Mestrado em Ciência Política), 2015.

FUNG, A. Varieties of Participation in Complex Governance. Public Administration Review, Dec. 2006.

GIBSON, R.; CANTIJOCH, M. Conceptualizing and Measuring Participation in the Age of the Internet: Is Online Political Engagement Really Different to Offline? The Journal of Politics, v. 75, n. 3, p. 701-716, July 2013.

HAFNER-FINK, M.; ČRNIČ, T. O. Digital Citizenship as Multiple Political Participation? Predictors of Digital Political Participation in Slovenia. Teorija in Praska, Ljubljana v. 51, n. 6, p. 1284-1303, 2014.

HIDMAN, M. The Myth of Digital Democracy. Princeton: Princeton University Press, 2009.

HJAVARD, S. Midiatização: teorizando a mídia como agente de mudança social e cultural. Matrizes, São Paulo v. 5, n. 2, p. 53-91, jan.-jun. 2012. Disponível em: $<$ http://www.revistas.univerciencia.org/index.php/MATRIZes/article/view/8139/7505>. Acesso em: set. 2015.

LIVINGSTONE, S. Internet Literacy: a negociação dos jovens com as novas oportunidades online. Matrizes, São Paulo, v. 4, n. 2, p. 11-42, jan./jun. 2011. 
HANSEN, J; FERREIRA, M. A. S. Da polarização à busca pelo equilíbrio: as relações entre internet e participação política

MARGETTS, H. The Internet and Democracy. In DUTTON, W. H. (Org.). The Oxford Handbook of Internet Studies. Oxford, UK: Oxford University Press, 2013.

MENDONÇA, R. F.; AMARAL, E. Racionalidade online: provimento de razões em discussões virtuais. Opinião Pública, Campinas, v. 22, n. 2, ago. 2016.

MILAN, S. When Algorithms Shape Collective Action: Social Media and the Dynamics of Cloud Protesting. Social Media + Society. https://doi.org/10.1177/2056305115622481, 2015

MOSSBERGER, K. Toward Digital Citizenship: Addressing Inequality in the Information Age. In: CHADWICK, A.; HOWARD, P. The Routledge Handbook of Internet Politics. New York: Routledge, 2009.

NORRIS, P. Digital Divide: Civic Engagement, Information Poverty and the Internet Worldwide. Cambridge: Cambridge University Press, 2001. Disponível em: $<$ http://www.hks.harvard.edu/fs/pnorris/Books/Digital\%20Divide.htm>. Acesso em: out. 2014.

NORRIS, P.; CURTICE, J. If You Build a Political Website, Will They Come? The Internet and Political Activism in Britain. International Journal of Electronic Government Research, v. $2, \quad$ n. $2, \quad$ p. 1-21, Apr.July, 2006. Disponível em: $<$ http://www.hks.harvard.edu/fs/pnorris/Articles/Articles\%20published\%20in\%20journals_fil es/IJEGR\%20Website\%20Norris\%20and\%20Curtice.pdf>. Acesso em: dez. 2014.

NUNES, R. Organisation of the Organisationless: Collective Action after Networks. Lüneburg, University of Lüneburg, 2014.

OLIVEIRA, R. A. et al. Política e juventude: participação política dos jovens no Sul do Brasil. Revista Debates, Porto Alegre, v. 10, n. 3, p. 189-222, set./dez. 2016. Disponível em: <http://seer.ufrgs.br/index.php/debates/article/view/70026/39706>. Acesso em: jan. 2017.

OSER, J.; HOOGHE, M.; MARIEN, S. Is Online Participation Distinct from Offline Participation? A Latent Class Analysis of Participation Types and Their Stratification. Political Research Quarterly, v. 66, n. 1, p. 91-101, Mar. 2013.

PARISER, E. O filtro invisível: o que a internet está escondendo de você. Rio de Janeiro: Zahar, 2012.

RIBEIRO, E.; BORBA, J.; HANSEN, J. R. Participação on-line e off-line no Brasil: relações e condicionantes. Revista do Serviço Público, Brasília, v. 67, n. 4, p. 497-523, out./dez. 2016. Disponível em: <https://revista.enap.gov.br/index.php/RSP/article/view/1262/781>. Acesso em: jan. 2017.

SILVEIRA, S. A. Novas dimensões da política: protocolos e códigos da esfera pública interconectada. Revista de Sociologia e Política, Curitiba, v. 17, n. 34, p. 103-113, out. 2009. Disponível em: <http://www.scielo.br/pdf/rsocp/v17n34/a08v17n34.pdf>. Acesso em: jan. 2015.

THEOCHARIS, Y. The Conceptualization of Digitally Networked Participation. Social 
Media + Society, p. 1-14, July/Dec. 2015.

THOMPSON, J. A mídia e a modernidade: uma teoria social da mídia. Tradução de: BRANDÃO, W. de O. 4. ed. Petrópolis, RJ: Vozes, 1998.

TRERÉ, E. Distorsiones tecnopolíticas: represión y resistencia algorítmica del activismo ciudadano en la era del "big data". Trípodos, n. 39, p. 35-51, dic. 2016.

Reclaiming, Proclaiming and Maintaining Collective Identity in the \#YoSoy132 Movement in Mexico: an Examination of Digital Frontstage and Backstage Activism through Social Media and Instant Messaging Platforms. Information, Communication and Society, v. 18, n. 8, p. 901-915, May. 2015. Disponível em: $<$ https://doi.org/10.1080/1369118X.2015.1043744>.

TUFEKCI, Z. The Medium and the Movement: Digital Tools, Social Movement Politics and the End of the Free Rider Problem. Police and Internet, v. 6, n. 2, p. 202-208, June 2014.

VALENZUELA, S. Analisando o uso de redes sociais para o comportamento de protesto: o papel da informação, da expressão de opiniões e do ativismo. Tradução de: PERANI, L. Revista Compolítica, Rio de Janeiro, v. 1, n. 4, jan./jun. 2014.

VALENZUELA, S.; ARRIGADA, A.; SCHERMAN, A. The Social Media Basis of Youth Protest Behavior: the Case of Chile. Journal of Communication, v. 62, n. 2, p. 299-314, April 2012.

VERBA, S.; SCHLOZMAN, K. L.; BRADY, H. Voice and Equality: Civic Voluntarism in American Politics. Cambridge, Mass.: Harvard University Press, 1995.

XENOS, M.; MOY, P. Direct and Differential Effects of the Internet on Political and Civic Engagement. Journal of Communication, v. 57, n. 4, p. 704-718, Dec. 2007. 